http://dx.doi.org/10.12795/PH.1989.v04.i02.27

\title{
ELEMENTOS CONSTITUTIVOS DEL HECHO TEATRAL: HACIA UNA DEFINICIÓN TEÓRICA
}

Rafael Portillo Andrés Pérez ${ }^{1}$

En las últimas décadas han proliferado los estudios teóricos sobre el hecho teatral, prestando siempre especial atención a la ambivalencia del teatro como manifestación literaria y a la vez espectáculo. Una importante contribución en este sentido ha sido la de los estudios semiológicos sobre el tema ${ }^{2}$. Al abordar el fenómeno teatral, la crítica ha sido casi siempre unánime al distinguir dos elementos diferentes e inseparables: texto y representación, expresando esta dualidad mediante conceptos como texto $\mathrm{A}$ y texto $\mathrm{B}$, texto dramático y texto teatral, drama y teatro, literatura y espectáculo, etc. Es también unánime la crítica al considerar que la propia especificidad del teatro sitúa a éste en una categoría un tanto aparte, diferenciada de las otras manifestaciones literarias y espectaculares.

Esa ambivalencia consustancial al teatro es también causa de no pocas impreciones y ambigüedades a la hora de abordar su estudio, a lo que se une una gran disparidad de enfoques críticos y la falta de coherencia terminológica. El presente trabajo pretende reflexionar sobre el complejo engranaje que hace posible el teatro, analizando sus elementos constituidos con la máxima claridad y un mínimo número de términos especializados, usando tan sólo sentido común y la experiencia personal en este campo.

1 Los autores recogen aquí las opiniones y comentarios de Teresa García-Perla, Rafael Astola, Sofía García, Rosario de la Prada, Angeles Toda, Pilar Nordmann, Pilar Benito, Inmaculada Gordillo, Ana Ma Garrido, Matilde Duque, Francisco Deco y Miguel A. Requejo, que fueron alumnos y compañeros en la asignatura de tercer ciclo «Cómo analizar un texto dramático», durante el curso 1987-88.

2 Resulta de todo imposible citar todos los nombres asociados a los estudios de semiología del teatro, pero basten al menos los de Urrutia, Díez Borque, Sito Alba y Bobes en España, Eco, de Marinis y Bettetini en Italia, Barthes y Pavis en Francia y Elam en Inglaterra-Italia. 
La mayoría de las obras teatrales se basan en un texto escrito que sirve de guía a la representación, que es lo que presencia el publico. Cabe hablar por tanto de «literatura» que genera un «espectáculo». Algunos estudiosos —entre ellos muchos semiólogos - han dado el nombre de «texto» a ambos elementos, pero en este trabajo se han preferido los términos «texto dramático» y «representación», entendiendo por tales la primera y la última fase de todo el proceso que conduce al estreno, por medio de un montaje. En el montaje de una obra intervienen hoy director, escenógrafo, actores, y personal de los equipos artístico y técnico, y para facilitar su labor se traza previamente un plan de trabajo que se suele plasmar en el libro o cuaderno del director y en los libretos de luces, sonido, utilería, etc. A todo este plan de trabajo se le denominará de aquí en adelante «proyecto de montaje», por cuanto a partir de él se desarrollará el montaje; dicho proyecto constituye el paso teórico intermedio entre el texto y la representación, y de su acertada puesta en práctica depende en gran medida el éxito o fracaso de todo. De aceptarse este planteamiento habrá que convenir en que los elementos constitutivos del hecho teatral son básicamente tres: texto, proyecto de montaje (cuya realización práctica dará lugar a los ensayos, diseños y demás) y representación. De los tres, tan sólo uno es teóricamente efímero: la representación; el texto y el proyecto de montaje se suelen poner por escrito y por tanto pueden llegar a publicarse, por lo que tienen asegurada una cierta permanencia. Se analizan a continuación las características de cada uno y su función dentro del fenómeno teatral.

El Diccionario de la Real Academia ofrece la siguiente definición de texto: «Todo lo que se dice en el cuerpo de la obra manuscrita o impresa, a diferencia de lo que en ella va por separado, como portadas, notas, índices, etc.». Habrá que partir pues de la base de algo escrito que constituye una «obra». En la historia del teatro existen ejemplos de espectáculo sin texto — es el caso de la «comedia del arte»- al haberse transmitido el argumento de forma oral, pero la mayoría de las obras han contado con un texto escrito; incluso las diversas variedades de teatro mudo tales como el mimo, el cuadro vivo o piezas como Acto sin palabras de Beckett o las del llamado "perfomance art», todas se basan en un guión previamente trazado, que en muchas ocasiones ha sido publicado. Se debe entender pues por Texto la obra escrita que sirve de base a un espectáculo, y en calidad de tal habrá que aceptar su carácter literario, con entera independencia del mérito artístico, al igual que se consideran literatura la novela, el poema y el relato. Por una antigua convención se han catalogado como literarios sólo los parlamentos y diálogos, pero no las acotaciones; sin embargo, la existencia de la obra dramática de Valle-Inclán así como la fama adquirida por Acto sin palabras obligan a un replanteamiento de la cuestión y a considerar que todo cuanto forma parte del texto dramático constituye la literatura dramática.

Los textos están formados en su mayor parte por parlamentos, ordenados éstos a su vez en pasajes dialogados, si bien los monólogos y los soliloquios poseen también plena entidad dramática. En las piezas para un solo personaje el monólogo se suele disfrazar de diálogo dirigido a seres imaginarios o directamente al público. Las acotaciones, cuya cantidad oscila enormemente de un autor a 
otro, son indicaciones teóricamente escritas para el director y los actores y se refieren a cuestiones de caracterización, decorados, movimiento escénico, etc., por lo que no se llegan a transmitir al público en el curso de la representación; para distinguirlas de los parlamentos, los editores suelen escribirlas con letra cursiva o entre paréntesis. Existen también unas acotaciones veladas, entendiendo por tales las observaciones que casualmente hacen los personajes al hablar acerca de cuestiones como al aspecto del decorado o el movimiento de los demás personajes; se las suele conocer como acotaciones «insertas» o como «decorado verbal» y pueden revestir singular importancia para director y actores.

En el texto dramático son los propios personajes, con entera independencia del autor o sin su aparente intervención, los que explican el desarrollo de la acción y suministran todos los datos sobre lo que ocurre en escena y fuera de ella. La figura del narrador resulta pues ajena al texto dramático, si bien conviene recordar que en el teatro clásico los coros y mensajeros desempeñaban hasta cierto punto la labor de narradores, mientras que en época mucho más reciente -el teatro político y muy especialmente el de Brecht - se ha vuelto a emplear la figura del narrador como elemento de «distanciamiento» o para transmitir con claridad un determinado mensaje. Naturalmente, al ser los personajes mismos quienes cuentan indirectamente lo que ocurre, se establecen diversos puntos de vista, ninguno de los cuales tiene que ser forzosamente asociado con el del autor. Cada personaje asume en efecto su propio punto de vista, y debe hacerlo con el suficiente convencimiento, de manera que no reste credibilidad a la caracterización y a la ficción de la que forma parte; ni siquiera en las farsas y en los melodramas más grotescos pueden perder los personajes su capacidad de defender un determinado punto de vista sin que se resienta toda la obra. De todo lo cual se deduce que es característico del texto teatral el uso de la segunda persona, frente a la «tercera» que caracteriza a la novela, y a la «primera» del poema lírico y del relato autobiográfico.

Corresponde igualmente al texto dramático el uso del tiempo presente, frente al pasado de la narrativa o la atemporalidad de la lírica. Al igual que ocurre en la novela y el relato, todo cuanto figura en el texto aparece como cierto, pero además se presenta como si realmente ocurriera en presencia del espectador, de forma simultánea. De ahí que el texto dramático deba contener unos mínimos elementos que doten de verosimilitud lo que se presenta en escena; una apoyatura especialmente eficaz en este sentido es la existencia de efectos especiales, destinados a producir la sensación de que todo cuanto presencia el espectador está teniendo realmente lugar.

Sin embargo y debido a la corta duración de un espectáculo teatral, los autores suelen recurrir al comienzo «in medias res» en un intento de «ganar tiempo» a los hechos que se propone escenificar. De ese modo, al levantarse el telón o al encenderse las luces de la escena ya ha ocurrido algo importante que el espectador deberá ir conociendo a medida que trascurre la acción; por eso, junto al predominio indiscutible del tiempo presente en los diálogos no es infrecuente la alusión a hechos pasados, que algunos de los personajes irán contando de forma más o menos velada dentro de los mismos diálogos o en determinados monólogos. Al 
comienzo mismo de Hamlet, antes incluso de que aparezca el fantasma para revelar las circunstancias de su asesinato, ya se ha aludido a las apariciones fantasmales y se intuyen los grandes males que amenazan a la corte danesa; Edipo Rey empieza con los lamentos por la desolación de Tebas, a causa de crímenes cometidos en el pasado, debiendo el propio Edipo llevar a cabo la investigación que revelará al público de la sala y a sí mismo la verdad.

Realmente, el problema principal al que se enfrenta el autor de obras de teatro es la limitación de espacio y tiempo, pues sabe que escribe para un escenario concreto, de dimensiones relativamente pequeñas, y para una función que casi nunca dura mucho más de dos horas. El novelista puede dar rienda suelta a su fantasía y plantear con toda libertad su relato, pero el dramaturgo se ve obligado a sacar el máximo partido de las estrechas coordenadas en que se mueve; por eso tiende a economizar al máximo sus recursos, de manera que con los mínimos medios pueda expresar un mayor número de ideas y sensaciones. En el teatro, un leve apagón puede sugerir el paso de tres años, un resplandor puede ser una hoguera o el incendio de Roma, el silbido de un tren puede indicar un viaje por toda América, etc. Quizá se estuviera refiriendo Ortega a esta capacidad evocadora del teatro cuando lo definía como «metáfora corporizada» y «metáfora visible». En cualquier caso, el texto dramático se caracteriza siempre por la máxima concentración de todos sus elementos.

A diferencia de otros textos literarios, el dramático aporta una cantidad importante de términos especializados, si bien por formar parte de las acotaciones no llegarán a oídos del público, que es el único receptor teórico del drama. Sin embargo el lector necesita familiarizarse con nombres de uso corriente como «acto», «jornada», «escena» y «cuadro», y con otros menos comunes como «foro», «mutis», «cenital», «caja», etc. todos los cuales aluden a cuestiones de organización técnica.

Un rasgo característico que el texto dramático comparte con el guión cinematográfico es su transmisión lineal, de principio a fin, sin posibilidad alguna de repetición. Por el contrario la novela, y hoy ya también la televisión, gracias al vídeo, permiten retroceder para volver sobre aquello que no se ha comprendido o que ha gustado más. Esto hace que el texto dramático se sitúe en clara desventaja con respecto a otras formas literarias, al tener que ser por pura necesidad reiterativo y lo suficientemente «claro» como para que llegue íntegramente o en su mayor parte al espectador; de hecho, el autor sabe que si el público no capta el sentido de alguna escena acabará por aburrirse y dejará de interesarle lo que ve. De ahí la servidumbre que todo texto tiene con respecto al público para el que se ha escrito. Quizá sea debido a esta circunstancia por lo que se ha acusado frecuentemente al teatro de ir a la zaga de las vanguardias literarias y artísticas; de hecho mientras la experimentación ha sacudido todas las formas artísticas a lo largo del siglo XX, el drama se ha conformado con un discreto segundo puesto, introduciendo más innovaciones técnicas que literarias o estéticas. En la actualidad y debido a la subvención estatal de que gozan muchas compañías, quizás se llegue a invertir esa dinámica - el estreno de una obra como El público de Lorca habría sido inviable en el teatro comercial- pero no ocurrirá mientras autor, director y actores dependan de la recaudación en taquilla para su subsistencia. 
La transmisión lineal y simultánea del texto plantea además el problema adicional del tiempo, que tanto preocupó a los preceptistas de otras épocas. Está claro que frente a las dos horas de la función, la ficción que se representa puede durar días, meses e incluso años; de ello se deduce que el tiempo ficticio no tiene necesariamente que coincidir con el tiempo real del espectáculo. Al menos tres módulos temporales distintos se reflejan en el texto: las dos horas que debe durar su puesta en escena, el tiempo en que transcurre la historia que se representa y el que emplean teóricamente los personajes en llevar a cabo cualquier acción concreta en el escenario. Al final de Doctor Fausto de Marlowe las campanadas que deben sonar cada media hora se empiezan a oir a intervalos cada vez más cortos, acrecentándose así la sensación del paso rápido del tiempo; esas campanadas representan además toda la noche, la última que pasa Fausto antes de morir y condenarse.

El texto dramático es ficción, no sólo porque presenta hechos y personajes ficticios, sino porque al ser declamado o dicho sobre un escenario debe aparentar que no es un texto escrito, sino diálogo espontáneo e improvisado. Esta cualidad hace que el texto dramático sea muy distinto a la novela, si bien lo asemeja al guión cinematográfico y televisivo.

A diferencia de otras formas literarias, el drama es un texto incompleto, al necesitar forzosamente el complemento de la puesta en escena. Los textos dramáticos no se escriben teóricamente para ser leídos, sino para ser representados, por lo que la mayoría no se imprimen hasta después de haber triunfado en un teatro. En algunos casos excepcionales - Bernard Shaw y Valle-Inclán, por ejemplocuando el autor cree que su obra no se va a representar nunca, la publica añadiéndole diversos elementos propios de la novela, para hacer más atractiva su lectura. En los demás casos el texto no llega directamente al público, sino que atraviesa primero el largo proceso que se inicia con el proyecto de montaje y culmina en el estreno; por eso más que producto acabado se le considera como una mera propuesta de montaje o, para usar un concepto cinematográfico, como el guión de la puesta en escena.

El texto dramático, dadas sus especiales características, no se transmite directamente, ni tampoco de forma privada e individual como sucede con la novela, el poema, la televisión o el vídeo, ya que, al igual que el cine, se trata de una actividad social.

Interesado el autor en que su obra se transforme en espectáculo, trata de acomodarse a las posibilidades económicas, técnicas y artísticas de la compañía que la vaya a representar y del local donde se vaya a estrenar. En la historia del teatro se han dado innumerables casos de autores que han creado sus personajes en función de actores concretos, que han organizado los elementos escenográficos según las condiciones de un determinado espacio escénico, que han eliminado personajes para abaratar costes o que han suprimido papeles femeninos cuando no han contado con suficientes mujeres o con muchachos barbilampiños. A mediados de los 70, cuando la crisis del petróleo obligó a hacer economías, muchas compañías empezaron a pedir piezas con pocos personajes y un solo decorado. El hecho de que aún hoy escaseen los papeles infantiles se debe a las duras condiciones 
de trabajo de los actores, obligados hasta hace poco a dar dos funciones diarias. De todo ello se deduce que el texto está sujeto a todo tipo de condicionantes extraliterarios, que deben ser tenidos en cuenta a la hora de plantearse un análisis serio o un nuevo proyecto de montaje. El valor teatral de un texto se mide por las posibilidades que ofrece para convertirse en espectáculo; es lo que se conoce como la «teatralidad» de un texto. Se puede dar el caso - y de hecho se ha dado- de que una obra de gran valor literario haya fracasado rotundamente en el escenario por carecer de teatralidad.

El proyecto de montaje comienza a tener entidad desde principios del siglo $\mathrm{XX}$, cuando adquiere relieve la figura del director. Es un proyecto que se pone por escrito tras una etapa previa de planificación, y que luego irá sufriendo modificaciones a medida que avance el montaje. Lo normal es que responsables artísticos y técnicos hagan sus anotaciones de forma particular y privada en sus correspondientes cuadernos y libretos, pero de un tiempo a esta parte se está tendiendo a publicar de forma parcial o resumida detalles de ese proyecto, coincidiendo con el estreno de la obra. Suele aparecer junto con el texto, en un libro de bello formato, a medio camino entre el programa de mano de lujo y la edición crítica, donde director, autor (o adaptador), escenógrafo, técnicos y a veces incluso críticos, exponen sus ideas sobre la obra y el montaje, y explican la filosofía que impregna esa puesta en escena concreta ${ }^{3}$. Es una iniciativa importante, donde tienen primacía aspectos puramente teatrales, y como tal debe considerarse de gran interés para profesionales y aficionados.

El proyecto de montaje modifica siempre de alguna forma el texto dramático original, para adaptarlo a las circunstancias del momento presente. En el caso de obras clásicas se suelen acortar monólogos y parlamentos redundantes y se suelen sustituir explicaciones retóricas por efectos visuales. Una obra moderna puede sufrir alteraciones en su texto para acrecentar un efecto cualquiera. Hoy está de moda «actualizar» obras antiguas presentándolas con atuendo y situaciones del mundo moderno, lo que conlleva ciertos cambios en el texto, para evitar anacronismos. Ocurre con frecuencia que las obras que se publican acusan las sucesivas transformaciones a que han estado sometidas durante los montajes; un ejemplo muy significativo es El señor de Pigmalión de Jacinto Grau, de la que existen al menos tres versiones distintas. Se puede afirmar por tanto que el proyecto de montaje es efecto y además causa del texto dramático, así como la representación es en definitiva efecto y causa de texto y proyecto: el público se encarga de hecho de hacer llegar sus reacciones a director y autor, y éstos hacen luego los cambios oportunos para mejorar el espectáculo. Esa interacción, que los ingleses y americanos denominan «feedback», es algo consustancial al teatro, que se puede dar en raras ocasiones en la novela pero que no puede existir en el cine ni en la grabación de vídeo, ya que una vez terminada la filmación y el montaje el film o la cinta repre-

3 En España han publicado libros de estas características el Centro Dramático Nacional (Eduardo II, Madre Coraje, Julio César, etc.) y el Teatro Español de Madrid (La Casa de Bernarda Alba, El castigo sin venganza, El sueño de una noche de verano, etc.), aunque es también práctica habitual en otros países, especialmente Inglaterra. 
senta un producto acabado y definitivo. Por el contrario en el teatro, un fallo de la primera función se puede corregir ya en la segunda.

Aunque entre la realización del proyecto de montaje de una obra cualquiera y su estreno puede transcurrir teóricamente un largo espacio de tiempo, lo normal es que al proyecto siga inmediatamente el montaje y la puesta en escena, por lo que entre proyecto y representación sólo median varias semanas o meses. Se puede considerar pues que ambos coinciden cronológicamente, mientras que entre texto y proyecto de montaje pueden mediar años e incluso siglos. Así pues el director que hoy se proponga montar una obra de Lope de Vega, por ejemplo, se encuentra cronológicamente muy alejado del texto pero muy cercano al público que presenciará la representación; se tendrá que esforzar por tanto en provocar el interés de ese espectador de hoy, evitando cualquier enfoque «arqueológico» que tal vez aplaudieran algunos historiadores y críticos literarios pero que traicionaría la esencia misma del teatro.

Un texto cualquiera se presta a interpretaciones muy diversas y por tanto puede dar pie a numerosos montajes. Sin embargo un proyecto de montaje es ya resultado de una interpretación concreta del texto, y significa una opción de entre las muchas posibles. Un director moderno que, por ejemplo, decidiera presentar al Segismundo de La vida es sueño como al libertador en una dictadura, estaría optando por una lectura muy concreta del texto de Calderón. Por eso y aunque los textos están también sujetos a cambios, como se ha visto más arriba, se puede afirmar que el texto es permanente, mientras que el proyecto de montaje es circunstancial y la representación es por naturaleza efímera. Un mismo texto puede ser escenificado de maneras completamente distintas, según el director y la compañía que se haya encargado del montaje. De ahí que muchos autores modernos se hayan querido encargar personalmente de la puesta en escena de sus obras: Brecht lo hizo en su día, y en fecha más reciente lo han hecho también Marsillach, Fernán Gómez, etc.

Cuando termina la última función ya no queda más constancia del montaje que las reseñas de prensa y las fotos. Todas las otras huellas de ese inmenso esfuerzo se borran inmediatamente. Por eso se recurre hoy al vídeo, en un intento de «congelar» en cinta la efímera vida del espectáculo. Sin embargo el vídeo resulta ser un pobre sucedáneo de la representación, al no poder reproducir factores tan importantes como la tercera dimensión o la inmediatez del público, aparte de reflejar de forma muy imperfecta los cambios luminotécnicos y de seleccionar de modo arbitrario el punto de vista del espectador. Mucho más efectivos resultan el cuaderno de dirección y los bocetos de escenografía y vestuario (y en definitiva cuanto constituye el proyecto de montaje), con los cuales se puede lograr una cierta reconstrucción de un determinado montaje. Este parece que fue el procedimiento seguido por Nuria Espert cuando hace unos años repuso la versión de Yerma que estrenara Victor García en 1972.

Se afirma más arriba que el valor de un texto dramático está en función de su teatralidad, pero habría que matizar que esa teatralidad se mide también por la capacidad que tiene una obra para dar lugar al mayor número posible de proyectos de montaje. 
El proyecto de montaje enriquece siempre al texto, no sólo porque le brinda la oportunidad de añadir elementos nuevos, sino sobre todo porque desarrolla al máximo las posibilidades dramáticas de diálogos y situaciones, trazando movimientos y gestos, disponiendo personajes en escena -incluso los que permanecen callados - organizando los efectos de luz, las pausas, decorados, efectos especiales y todo cuanto contribuye a la puesta en escena. En definitiva el montaje sirve para traducir en acción la literatura dramática, haciéndola asequible a un público que en teoría no tiene por qué estar al tanto de cuestiones literarias.

Pero no hay que olvidar que el esfuerzo desplegado durante el montaje se encamina hacia una eficaz puesta en escena. Esta se puede considerar ultimada cuando, superados los últimos ensayos generales, se llega al consiguiente ensayo general con todo y al preestreno y estreno. De ese modo se entra en la tercera fase del proceso teatral, es decir, en la representación. Sin embargo, al final de la segunda fase y al comienzo de la tercera puede producirse una cierta ambigüedad, ya que los límites entre lo que es un ensayo «especial» y la auténtica función pueden quedar un tanto imprecisos. En cualquier caso, se puede considerar auténtica representación aquella que tiene lugar delante de público ajeno a la empresa y a la compañía, es decir, cuando los espectadores que la contemplan son imparciales.

Es precisamente en la representación cuando por fin se ponen a prueba todos los recursos diseñados en las dos fases previas, pues el público es la única piedra de toque de un espectáculo. En la mayoría de los teatros -incluso en los menos convencionales- se produce una situación de «enfrentamiento», al situarse los actores en un área concreta y definida (el espacio escénico o escenario) para ser contemplados por los espectadores desde sus asientos de la sala. El papel del público es mucho más pasivo, pero su comportamiento afecta siempre el trabajo de los actores y el ritmo del espectáculo, pues los murmullos, las risas, el silencio, los aplausos, las protestas y cualquier otra reacción influye en lo que ocurre en escena; es de sobras sabido que el actor profesional deja de hablar mientras el público ríe, que alza la voz cuando se produce ruido en la sala y que acorta escenas cuando éstas no producen el efecto apetecido.

También los actores pueden influir decisivamente sobre la representación y sobre los espectadores. En primer lugar conviene recordar la difícil situación del actor, obligado a tomar parte en una doble ficción, pues asume una personalidad ajena - la de su personaje - y finge hablar y escuchar a otros actores, cuando en realidad se dirige siempre al público y conoce de memoria tanto lo que va a decir como la respuesta de su interlocutor. En esas circunstancias resulta muy difícil actuar con naturalidad, y sin embargo ha de tender a ello, como se han encargado de enseñar tantos directores desde la época de Stanislavsky, pero sin perder nunca de vista que están actuando delante de un público, al que deben mantener interesado a lo largo de la representación. Por eso los actores acortan o alargan las escenas según convenga en cada momento, improvisan por medio de morcillas o repiten parlamentos cuando se produce un bache o una amnesia, cambian de posición cuando no ilumina adecuadamente un foco o les cubre otro actor, etc. 
Son tantos los factores humanos y técnicos que intervienen en la puesta en escena de cualquier espectáculo, que se puede afirmar que no hay jamás dos representaciones iguales. Incluso cuando en un día se dan dos funciones en un mismo teatro, una de tarde y otra de noche, ante públicos semejantes, cada una se caracterizará por algo diferente.

Aunque en el momento de la representación se conjugan casi todos los elementos que están presentes en el hecho teatral, lo normal es que el autor haya desaparecido tras los primeros ensayos y que el director se ausente tras el estreno. Tampoco son ya necesarios los escenógrafos y figurinistas, cuyo cometido ha concluido con los últimos ensayos. Únicamente si se desea llevar a cabo cambios importantes en el texto o en la puesta en escena serán necesarios autor, director o diseñadores artísticos y técnicos.

Hasta hace poco, actores y actrices se valían únicamente de sus propias dotes interpretativas durante toda la representación, ya que ésta se daba de forma directa, por medio de recursos más o menos artesanales. Sin embargo, las innovaciones tecnológicas de las últimas décadas han introducido numerosos e importantes cambios. La electrónica, por ejemplo, ha revolucionado la escena, y no sólo porque ha permitido el control de luz y sonido por ordenador, sino porque ha hecho posible el uso de micrófonos especiales (inalámbricos, unidireccionales y demás) que solucionan los problemas de acústica y mitigan el esfuerzo vocal de los actores.

Igualmente, los avances en el campo de la grabación magnetofónica han ocasionado que todos los efectos sonoros se realicen fuera del escenario y de la representación, con bastantes antelación a la fecha del estreno. Muchas veces, cuando canta el actor en escena sólo está moviendo los labios, mientras suena por los altavoces su propia voz grabada en un estudio; es el truco que en España se conoce como «playback». Se trata pues de un nuevo caso de ficción, ya que se intenta dar la impresión de que se está produciendo un sonido ya realizado; al mismo tiempo, se está alterando el esquema teórico del hecho teatral, ya quie elementos pertenecientes a la fase de montaje pasan a formar parte de la representación. Algo parecido ocurre con la proyección de diapositivas y películas de celuloide o de vídeo, todas las cuales son de uso bastante frecuente en espectáculos modernos, alternando o simultaneando con la acción del escenario. En algunos casos muy especiales la acción de los actores y la previamente filmada pueden confundirse o sustituirse mutuamente, como ocurría en la curiosa puesta en escena de Marsillach en Antes que todo es mi dama de Calderón, en 1988.

Se alude varias veces a lo largo de este trabajo al carácter ficticio del teatro y, al hablar de representación, es forzoso abundar una vez más en ello. Todo cuando presencia el espectador durante la función es fingido, pero se debe presentar como si fuera real. Los profesionales emplean de hecho la expresión «mentir» para referirse a cualquier acción simulada que aparece como auténtica en una representación: se mienten los golpes, un veneno, el paso del tren...; si no se mintiera la puñalada mortal que recibe un personaje, no volvería a ocurrir lo mismo, lógicamente, en la función siguiente. Ese elemento de ficción es lo que caracteriza al teatro como arte, y a la representación teatral como espectáculo, frente a otros 
espectáculos como los toros, el fútbol o el funambulismo, donde todo cuanto se ve - al menos teóricamente- ocurre de verdad.

Si se acepta el carácter efímero e irrepetible de la representación teatral, habrá que aceptar igualmente el carácter efímero e irrepetible de la experiencia que tiene cada espectador de la representación a la que asiste. No todas las personas presencian el espectáculo en las mismas condiciones visuales o acústicas, pues mientras unas lo hacen desde las primeras filas de butacas, otras están sentadas en el gallinero; tampoco verá la función de igual manera quien lo haga en un teatro al aire libre que quien acuda a un local con calefacción, en pleno invierno. No todo el mundo está atento a los mismos detalles al mismo tiempo; en el cine, un primer plano de un teléfono indica al espectador que ese es el objeto más importante del decorado, pero en el teatro cada persona dirige su mirada a lo que desea (el uso individual de los gemelos de teatro apunta hacia esa libertad del público) cuando quiere. No recibe la misma impresión quien acude al estreno que quien asiste a una de las últimas funciones; tampoco se encuentra en la misma disposición el espectador que se sienta en una sala semivacía que quien asiste a un lleno. Hay que tener además en cuenta que hasta hace poco el teatro era un lugar de encuentro, y que hasta bien entrado el siglo XX no se apagaron por completo las luces de la sala, con lo que el público formaba también parte de la función, y acudía tanto a ver la obra como a verse a sí mismo. De todo ello parece deducirse que tampoco existen dos espectadores que presencien exactamente la misma representación.

Tod́o el complejo entramado hasta aquí descrito puede dar una idea aproximada de la dificultad que entraña la definición teórica del hecho teatral. Sin embargo, no por ser una empresa ardua debe ser soslayada, por lo que tal vez estas páginas contribuyan, al menos, a descubrir la dimensión del problema. 